\title{
Leukocyte function-associated antigen 1 (LFA-1) and CD44 are signalling molecules for cytoskeleton-dependent morphological changes in activated $T$ cells
}

\author{
Dermot Kelleher, ${ }^{\star}$ Anne Murphy, ${ }^{*}$ Conleth Feighery, ${ }^{\dagger}$ and Eoin B. Casey ${ }^{\ddagger}$ \\ ${ }^{*}$ Department of Clinical Medicine, Trinity College Dublin and Departments of ${ }^{\ddagger}$ Rheumatology and ${ }^{\dagger}$ Immunology, \\ St. James's Hospital, Dublin, Ireland
}

Abstract: Signaling through the leukocyte function-associated antigen 1 (LFA-1) molecule has previously been shown to induce homotypic aggregation in $T$ cells and to induce cytoskeletal changes in $T$ lymphoma cells. In this study we describe the induction of a dendritic phenotype associated with cytoskeletal rearrangement in activated human peripheral blood $T$ cells stimulated with monoclonal antibody SPV-L7 to LFA-1 $\alpha$. Maximal expression of this phenotype required $72 \mathrm{~h}$ preactivation with phorbol myristate acetate and expression was abolished using the protein kinase $C$ inhibitor staurosporine. Monoclonal antibody to CD18, the $\beta$-chain of LFA-1, did not induce this phenotype. Monoclonal antibody MEM 83 to presumably a discrete epitope on LFA-1 $\alpha$ did not induce this phenotype but induced homotypic aggregation. However, a monoclonal antibody to CD44 induced a similar phenotype in activated lymphocytes. Induction of both homotypic aggregation and the dendritic phenotype was abolished by preincubation with soluble intracellular adhesion molecule 1 (ICAM-1). Cytoskeletal inhibitors prevented the morphological changes in SPV-L7-activated lymphocytes. Preincubation with tyrosine kinase inhibitor, protein kinase $C$ inhibitors, and inhibitors of new protein synthesis also prevented these morphological changes. These data suggest that discrete epitopes on LFA-1 $\alpha$ may be capable of inducing discrete signals either for homotypic aggregation or for a dendritic phenotype. As both LFA-1 and CD44 are involved in the migration of lymphocytes through high endothelial venules, these data could suggest that these molecules transduce signals resulting in cytoskeletal modification necessary for lymphocyte transmigration. J. Leukoc. Biol. 58: 539-546; 1995.

Key Words: $L F A-1 \cdot T$ lymphocyte $\cdot$ protein kinase $C \cdot C D 44$. integrin · homotypic aggregation · cytoskeleton - migration

\section{INTRODUCTION}

The integrin superfamily of membrane proteins includes the receptors for extracellular matrix proteins, leukocyte integrins, and the very late activation antigen (VLA) family of cell surface receptors [1]. The leukocyte integrin leukocyte function-associated antigen 1 (LFA-1) shares a common 95-kD $\beta$-chain, CD18, with the p150,95 molecule and the C3b receptor but utilizes a specific 180-kd $\alpha$ chain $\mathrm{CDIl}_{\mathrm{a}}$ [2] to form a membrane-expressed heterodimer. LFA-1 is frequently classified as an adhesion molecule based on its interaction with specific cellular receptors such as intracellular adhesion molecules 1 and 2 (ICAM-1 and ICAM-2) [3]. Intercellular adhesion necessary for help and cytotoxicity is abrogated by the use of antibodies to LFA-1 and its ligand ICAM-1 [4]. In addition, stimulation of $T$ cells by means of antibodies to CD3 provokes rapid homotypic aggregation, which may be inhibited by monoclonal antibodies to LFA-1 and ICAM-1 [5]. However, LFA-1 may also function as a signaling molecule. Specifically, antibodies to LFA-1 have been shown to potentiate calcium flux in activated $T$ cells [6]. Furthermore, an activated phenotype of LFA-1 functions as a signaling molecule for homotypic aggregation [7] and antibodies to LFA-1 were shown to stimulate cytoskeletal rearrangement in a human $\mathrm{T}$ cell line [8]. Previous studies have shown cytoskeletal association of several members of the integrin family $[9,10]$, and direct association of LFA-1 with cytoskeletal elements has also been observed in human $T$ cells [11]. This report describes the induction of morphological changes associated with cytoskeletal reorganization in activated $\mathrm{T}$ cells by stimulation with cross-linked antibodies to LFA-l $\alpha$. Preactivated T cells stimulated through anti-LFA-1 SPV-L7 underwent significant morphological change with the development of long "dendritic" processes. Similar changes were observed in $\mathrm{T}$ cells preactivated through the CD44 molecule, which is also involved in the regulation of $\mathrm{T}$ cell homing.

\footnotetext{
Abbreviations: HLA, human leukocyte antigen; ICAM-1, intracellular adhesion molecule 1; IgGl, immunoglobulin Gl; LFA-1, leukocyte function-associated antigen 1; PBS, phosphate-buffered saline; PKC, protein kinase C; PMA, phorbol myristate acetate; TNF- $\alpha$ tumor necrosis factor $\alpha$; VLA, very late activation antigen.

Reprint requests: Dermot Kelleher, Department of Clinical Medicine, Trinity College Dublin Medical School, St. James' Hospital, Dublin 8, Ireland.

Received May 12, 1995; revised July 18, 1995; accepted July 19, 1995.
} 


\section{MATERIALS AND METHODS}

\section{Cell lines and antibodies}

All cultures were made in RPMI 1640 containing $10 \%$ fetal calf serum, $100 \mathrm{U} / \mathrm{ml}$ penicillin, $100 \mu \mathrm{g} / \mathrm{ml}$ streptomycin, $5 \times 10^{-5} \mathrm{M}$ 2-mercaptoethanol, $2 \mathrm{mM}$ l-glutamine, and $1 \mathrm{mg} / \mathrm{ml}$ HEPES buffer. Antibody B7.13 to human leukocyte antigen (HLA) DR was a kind gift of Dr. T. M. Neri, Basel Institute for Immunology, as was the anti-class I antigen. Antibodies to LFA-1 $\alpha$ chain (IgGl) (clone SPV-L7) were purchased from Monosan Monoclonal antibodies (Sanbio bv. Uden, Netherlands) and MHM 24 from Dakopatts (Glostrup, Denmark). Other antibodies to LFA-1 included MEM 83 (Sanbio bv), which recognizes a determinant involved in the activation of homotypic aggregation [12], and MHM 23, which is directed against CD18, the $\beta$ chain of LFA-1. Antibody to CD3 was derived from a supernatant of the hybridoma obtained from the American Type Culture Collection. Anti-CD2 (Leu-5b, IgG2a) was purchased from Beckton Dickinson (Mountain View, CA). A second antiCD2 antibody (MT910) was purchased from Dakopatts. Anti-CD43 was purchased from Sanbio bv and L3Dl antibody to CD44 was a kind gift of Dr. M. B. Omary, Stanford University. Isotype-specific goat anti-mouse IgC2a was purchased from Southern Biotechnology (Teddington, Middlesex, UK). Staurosporine was purchased from Calbiochem, and soluble ICAM-l was purchased from British Biotechnology, Oxford, UK. The specific protein kinase C (PKC) inhibitor Ro-31-8220 was a kind gift of Dr. Trevor Hallam, Roche Pharmaceuticals, Welwyn Garden City, Herts, UK. Herbimycin A and Actinomycin D were purchased from Sigma.

\section{T cell enrichment}

T cells were enriched from peripheral blood mononuclear cells derived by Ficoll-Hypaque sedimentation. Enrichment was performed by plastic adhesion $(\mathrm{l}$ h) followed by nylon wool adherence (one pass). Cells were resuspended at $10^{6}$ cells $/ \mathrm{ml}$ and incubated for 24,48 , and $72 \mathrm{~h}$ in the presence and absence of phorbol myristate acetate (PMA), $25 \mathrm{ng} / \mathrm{ml}$, or OKT3 or combinations of OKT3 and anti-CD2 (MT910). In addition, we performed experiments using a submaximal dose $(5 \mathrm{ng} / \mathrm{ml})$ in combination with anti-CD3. Following incubation, cells were utilized in cytoskeletal studies. In some experiments, cells were preincubated with PMA in the presence of staurosporine at $10^{-7} \mathrm{M}$ or the PKC inhibitor Ro-31-8220 at $10 \mu \mathrm{M}$, doses previously established in our laboratory to be optimal in inhibition of PKC-mediated events. To determine whether new protein synthesis was required, cells were cultured in the presence or absence of $1 \mu \mathrm{g} / \mathrm{ml}$ cycloheximide or $1 \mu \mathrm{g} / \mathrm{ml}$ actinomycin D. Finally, we examined the role of tyrosine kinases in the development of dendritic processes by using the tyrosine kinase inhibitor herbimycin $A$ at $2-4 \mu \mathrm{M}$.

\section{Stimulation with anti-LFA-1}

These studies were performed using Labtek chamber slides (Nunc, Napierville, IL) Chamber slides were precoated with goat anti-mouse immunoglobulin by incubating overnight at $4^{\circ} \mathrm{C}$. Chambers were then coated with antibodies to either LFA- $\alpha$ (IgGl isotype), SPV1-7, MEM 83 or MHM-24, CD18, CD43, CD54, CD44, CD11, CD2, transferrin receptor, HLA-DR, CD3, or HLA-ABC. The chambers were then washed three times with phosphate-buffered saline (PBS), and $T$ cells either nonactivated or PMA preactivated were then added at a concentration of $10^{6} \mathrm{cell} / \mathrm{s} / \mathrm{ml}$. In some experiments activated $\mathrm{T}$ lymphocytes were preincubated with soluble ICAM-1. The chamber slides were then cultured at $37^{\circ} \mathrm{C}$ in a $5 \% \mathrm{CO}_{2}$ incubator and examined for the development of morphological change with extension of dendritic processes at $4 \mathrm{~h}$ using a Nikon phase-contrast microscope.

\section{Confirmation that cells expressing dendritic processes are $\mathrm{T}$ cells}

To confirm that the cells examined were in fact $T$ cells, phenotypic characterization was carried out by FACScan utilizing monoclonal antibodies to CD2 and CD3 before and after activation with PMA. Anti-LFA1 antibody MHM 24 was also used to determine whether there had been significant up-regulation of expression in the course of PMA activation.
CD2 immunohistochemical staining was also used to confirm that cells that had developed dendritic processes were in fact $T$ cells. For the detection of CD2-expressing cells, chambers were washed in PBS following stimulation with anti-LFA-1 as described above and stained for CD2 expression using Leu-5b, an IgG2a isotype antibody, using an isotype specific second antibody (Southern Biotechnology) and an immunoperoxidase technique with diaminobenzidine as the substrate. Counterstaining was with hematoxylin.

\section{Effects of cytoskeletal inhibitors}

In some experiments, a cytoskeletal inhibitor, cytochalasin B $(10 \mu \mathrm{g} / \mathrm{ml})$, colchicine $(50 \mu \mathrm{M})$, or vinblastine $(100 \mathrm{nM})$, or the metabolic inhibitor hydroxyurea $(1 \mathrm{mM})$ was also added.

\section{RESULTS}

\section{Morphological changes in T cells}

Three-day-activated $\mathrm{T}$ cells but not resting $\mathrm{T}$ cells stimulated with antibody SPV-L 7 to LFA-l $\alpha$ developed long dendritic processes on the majority of cells. Antibody MEM 83 , also to LFA-1 $\alpha$, induced homotypic aggregation but not expression of dendritic processes (Fig. 1). The processes induced by stimulation with SPV L-7 had a length of up to 10 times the transverse diameter of the cell soma. Processes developed within minutes of cell contact with the antibodycoated plate and continued to grow for up to $4 \mathrm{~h}$. The induction of dendritic processes required a full 3 days of prestimulation with PMA for maximal effect (Table 1) and was not significant after prestimulation for less than $24 \mathrm{~h}$. There was considerable interindividual variability in the response of activated cells to anti-LFA-1, with counts of dendritic processes ranging from approximately $20 \%$ to greater than $60 \%$. Preactivation with OKT3 also produced low levels of dendritic processes (Fig. 2). However, this was significantly augmented by the addition of either antiCD2 or a low dosage of PMA. Incubation with tumor necrosis factor $\alpha$ (TNF- $\alpha$ ) did not influence expression of dendritic processes. Stimulation with antibodies to other antigens, such as HLA class I (see Table 3) and HLA-DR and transferrin receptor expressed at high density on the cell surface, did not result in similar changes. Antitransferrin receptor stimulation resulted in flat adherent round lymphocytes with short processes circumferentially, usually no greater than $10-20 \%$ of the cell diameter.

\section{Dendritic phenotype is induced by specific epitopes on LFA-1 $\alpha$}

Dendrite formation was induced by monoclonal antibody SPV-L 7 to LFA- $1 \alpha$ but not by monoclonal antibody MHM 24 (Table 2). Induction of dendritic processes by both anti-LFA-1 and anti-CD44 was blocked by prior incubation with soluble ICAM-1. Antibody MEM 83 resulted in homotypic aggregation that was blocked by soluble ICAM-1 incubation. Anti-CD18, the $\beta$ chain common to the leukocyte integrins, failed to induce cytoskeletal rearrangement. AntiCD43 induced homotypic aggregation that was blocked by soluble ICAM-1. However, the anti-CD44 monoclonal antibody L3Dl induced changes similar to those mediated by 

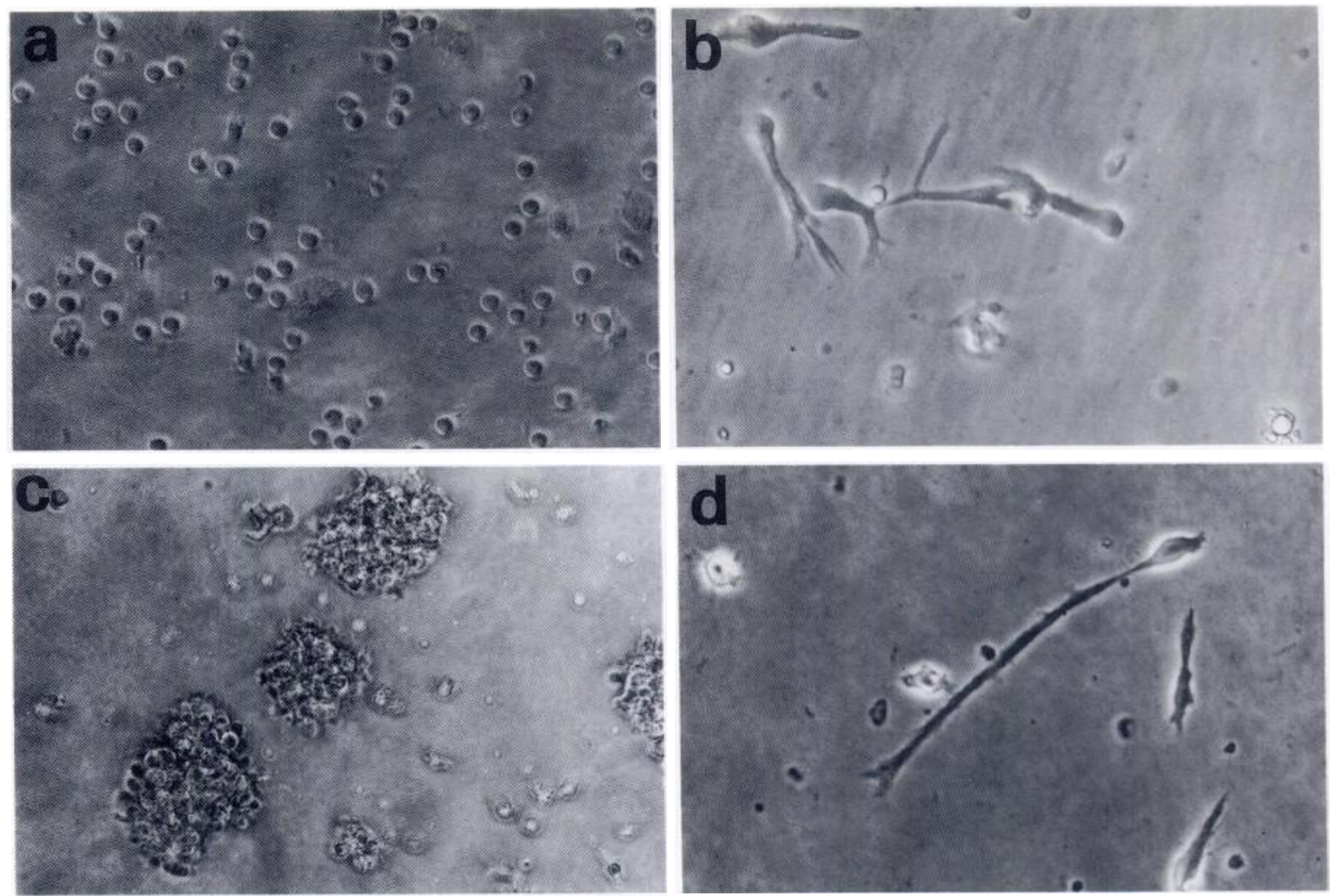

Fig. 1. Phenotype of lymphocytes stimulated through anti-LFA-1 $\alpha$ monoclonal antibodies. Three-day-activated T cells were stimulated with monoclonal antibodies to CD18 (a), SPV-L7 anti-LFA-1 $\alpha$ (b), and MEM 83, LFA-1 $\alpha$ (c). As can be seen, SPV-L-7 induced the expression of dendritic processes on $\mathrm{T}$ cells and MEM 83 induced homotypic aggregation. (d) Example of a dendritic process, induced by SPV-L-7, extending for more than 10 times the transverse diameter of the cell soma. Changes identical to those in (b) were observed with anti-CD44, and similar homotypic aggregation was also induced by anti-CD43.

anti-LFA-1 $\alpha$ (SPV L 7). Addition of staurosporine at the time of preactivation blocked induction of dendritic processes completely (Fig. 3). Staurosporine also prevented the induction of homotypic aggregation by MEM 83 and by anti-CD43 antibodies but did not alter cell viability. The addition of Ro-31-8220 produced effects similar to those of staurosporine. Inhibitors of protein synthesis including actinomycin $D$ and cycloheximide also blocked the development of dendritic processes when cells were preincubated. Finally, the tyrosine kinase inhibitor herbimycin signifi-

TABLE 1. Induction of Dendritic Processes in T Cells Preactivated with PMA ${ }^{a}$

\begin{tabular}{|c|c|c|c|c|c|c|}
\hline \multirow[b]{3}{*}{ Antibody } & \multicolumn{6}{|c|}{ T cells expressing dendritic processes $(\%)$} \\
\hline & \multicolumn{3}{|c|}{ No PMA } & \multicolumn{3}{|c|}{ PMA } \\
\hline & $24 \mathrm{~h}$ & $48 \mathrm{~h}$ & $72 \mathrm{~h}$ & $24 \mathrm{~h}$ & $48 \mathrm{~h}$ & $72 \mathrm{~h}$ \\
\hline No antibody & $<1$ & $<1$ & $<1$ & $<1$ & $<1$ & $<1$ \\
\hline Anti-class I & $<1$ & $<1$ & $1 \pm 1$ & $5 \pm 1$ & $6 \pm 2$ & $5 \pm 2$ \\
\hline Anti-LFA-1 & $<1$ & $<1$ & $1 \pm 1$ & $11 \pm 1$ & $27 \pm 2$ & $56 \pm 11$ \\
\hline
\end{tabular}

-T lymphocytes obtained from peripheral blood by Ficoll-Hypaque sedimentation followed by sequential nylon wool and plastic adherence steps were incubated in the presence or absence of $25 \mathrm{ng} / \mathrm{ml}$ PMA for 24,48 , and $72 \mathrm{~h}$ before stimulation with immobilized antibodies to LFA-1 and class I molecules in Labtek chamber slides. Following $4 \mathrm{~h}$ of stimulation, the percentage of cells expressing dendritic processes was counted using a Nikon phase-contrast microscope. Results are expressed as mean \pm SEM of four experiments.

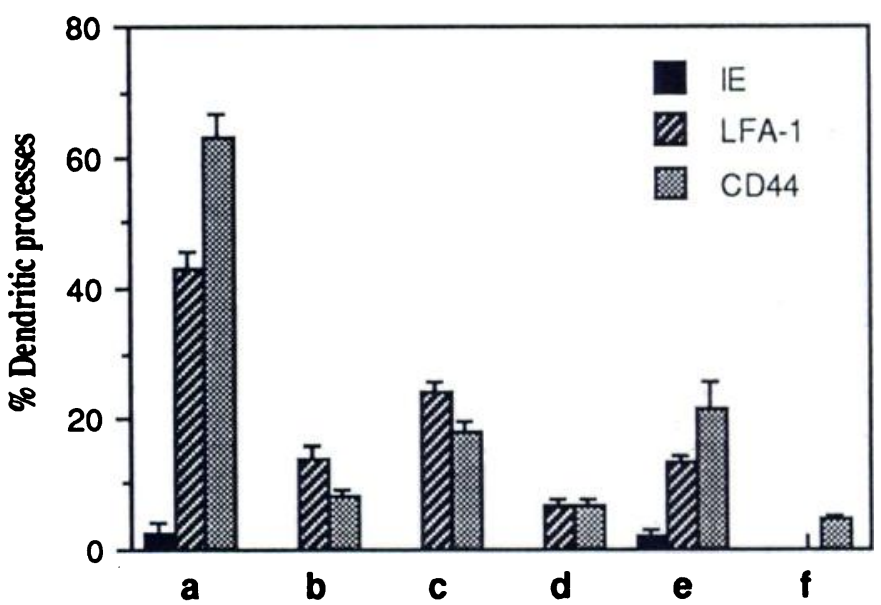

Fig. 2. Induction of dendritic processes in preactivated peripheral blood lymphocytes. Peripheral blood lymphocytes were preactivated in the presence of $25 \mathrm{ng} / \mathrm{ml} \mathrm{PMA} \mathrm{(a),} 5 \mathrm{ng} / \mathrm{ml}$ PMA (b), $5 \mathrm{ng} / \mathrm{ml} \mathrm{PMA} \mathrm{and} \mathrm{OKT3} \mathrm{(c),}$ OKT3 (d), OKT3 and anti-CD2 (e), and TNF- $\alpha$ (f). Preactivated cells were then stimulated for $4 \mathrm{~h}$ with immobilized antibodies to LFA-1 (hatched square), CD44 (dotted square), and an irrelevant antibody to mouse MHC, anti-IE (black square). Dendritic processes were counted, and the percentage positivity is represented by the histogram bars. Results are shown as mean and SE of triplicate counts in a representative experiment $(n=3)$. 
TABLE 2. Effects of Staurosporine and Soluble ICAM-1 on Induction of Dendritic Morphology ${ }^{a}$

\begin{tabular}{lccc}
\hline \hline & \multicolumn{3}{c}{ Cells undergoing dendritic morphology (\%) } \\
\cline { 2 - 4 } Antibody & Antibody alone & Antibody + SP & Antibody + sICAM-1 \\
\hline LFA-1a (SPV-7) & $46 \pm 3$ & 0 & 0 \\
LFA-1a (MEM 83) & HA & 0 & 0 \\
CD44 (L3D1) & $52 \pm 2$ & 0 & 0 \\
CD43 & HA & 0 & 0 \\
CD18 & $2 \pm 1$ & NT & NT \\
ICAM-1 & $2 \pm 1$ & NT & NT \\
LFA-1a & $3 \pm 1$ & NT & NT \\
(MHM-24) & & & \\
\hline
\end{tabular}

${ }^{a} \mathrm{~S}$, staurosporine; sICAM-1, soluble ICAM-1; HA, homopypic aggregation. T lymphocytes obtained from peripheral blood by Ficoll-Hypaque sedimentation followed by sequential nylon wool and plastic adherence steps were incubated in the presence or absence of $25 \mathrm{ng} / \mathrm{ml}$ PMA for $72 \mathrm{~h}$ prior to stimulation with immobilized antibodies to LFA-l and other adhesion molecules in Labtek chamber slides. Staurosporine was added at a concentration of $10^{-7} \mathrm{M}$ during preactivation. sICAM-l was added to $\mathrm{T}$ lymphocytes $\mathrm{l} \mathrm{h}$ prior to stimulation with antibodies. Homotypic aggregation was abolished by pretreatment with either staurosporine or soluble ICAM-l. Following $4 \mathrm{~h}$ stimulation, the percentage of cells expressing dendritic processes was counted using a Nikon phase-contrast microscope. Results are expressed as mean \pm SEM of four experiments.

cantly reduced the development of dendritic processes at a dose $(2 \mu \mathrm{M})$ that produced submaximal inhibition of lymphocyte proliferation and completely blocked development of processes at a dose producing complete inhibition of lymphocyte proliferation (Fig. 4). Herbimycin also produced a significant reduction in dendrite induction when added after $\mathrm{T}$ cell activation (Fig. 5), suggesting that tyrosine kinase activation may be important in mediating the effects of anti-LFA-1. The percentage of cells expressing dendritic processes was significantly reduced by cycloheximide and actinomycin D (Fig. 6).

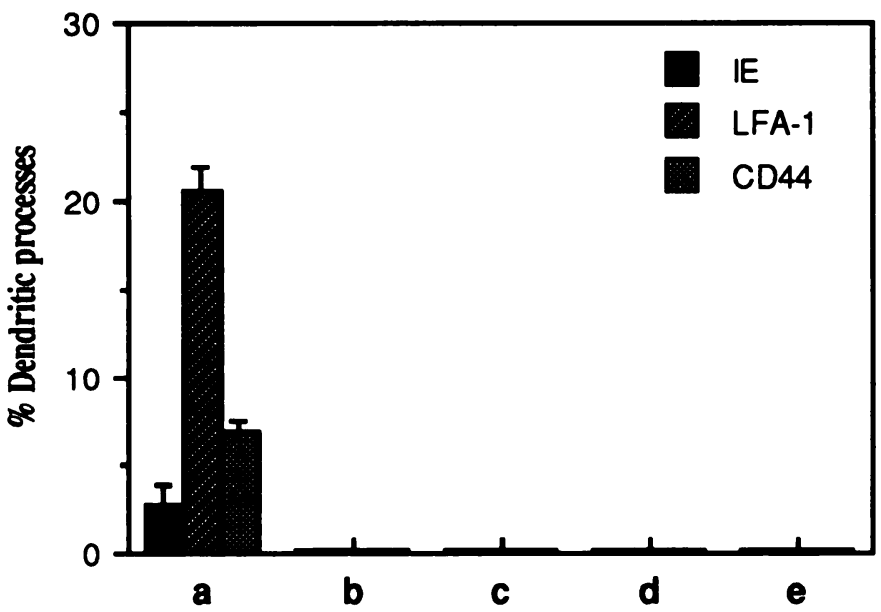

Fig. 3. Inhibition of formation of dendritic processes. Peripheral blood lymphocytes were preactivated for $72 \mathrm{~h}$ with $25 \mathrm{ng} / \mathrm{ml} \mathrm{PMA}$ in the absence or presence of inhibitors of protein synthesis, RNA synthesis, and protein kinase C. Subsequently, the cells were incubated with immobilized antibodies to LFA-1 (hatched square), CD44 (dotted square), and an irrelevant antibody, anti-IE (black square). Dendritic processes were inhibited with the addition of $1 \mu \mathrm{g} / \mathrm{ml}$ cyclohexamide (b), $10 \mu \mathrm{M}$ Ro-31-8220 (c), 10 $0^{-7}$ $M$ staurosporine (d), and $1 \mu \mathrm{g} / \mathrm{ml}$ actinomycin $\mathrm{D}(\mathrm{e})$. Results are shown as mean and SE of triplicate counts in a representative experiment $(n=4)$.

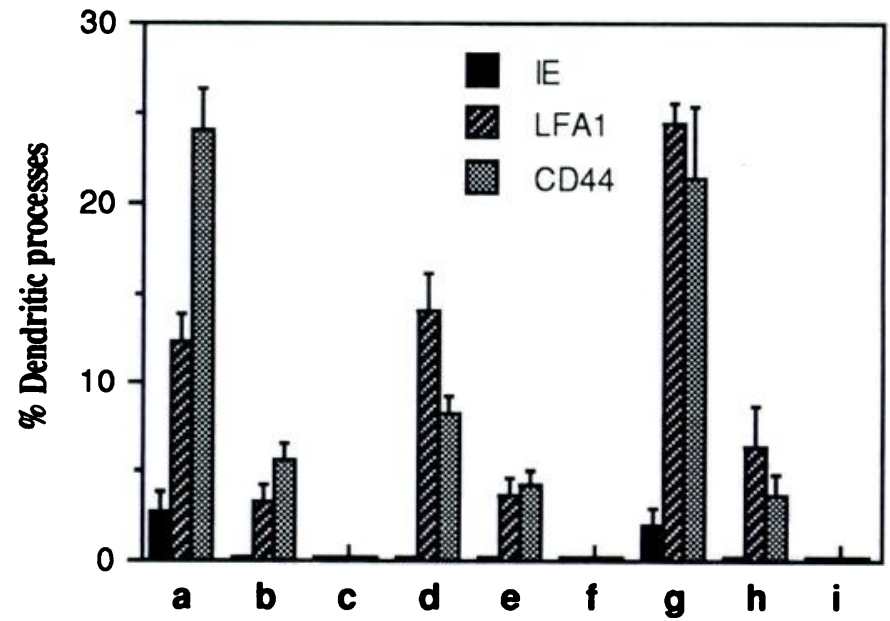

Fig. 4. Dose-dependent inhibition of dendritic processes by the tyrosine kinase inhibitor herbimycin. Peripheral blood lymphocytes were preactivated for $72 \mathrm{~h}$ with $25 \mathrm{ng} / \mathrm{ml}$ PMA (a) in the absence or presence of herbimycin $A$ at $2 \mu M$ (b) and $4 \mu M$ (c), with $5 \mathrm{ng} / \mathrm{ml}$ PMA (d) and herbimycin $A$ at $2 \mu \mathrm{M}$ (e) and $4 \mu \mathrm{M}$ (f), and with $5 \mathrm{ng} / \mathrm{ml} \mathrm{PMA} \mathrm{and} \mathrm{OKT3}$ (g) with herbimycin $A$ at $2 \mu M$ (h) and $4 \mu M$ (i). Subsequently, cells were incubated for $4 \mathrm{~h}$ with immobilized antibodies to LFA-l (hatched square), CD44 (dotted square) and an irrelevant antibody to mouse MHC anti-IE (black box). Results are shown as mean and SE $(n=3)$.

\section{Phenotype of activated T cells}

CD3 is frequently down-regulated by stimulation with PMA, and it is evident that the phenotypic data demonstrate a loss of CD3 expression on stimulation (Fig. 7a). Nonetheless, CD2 remains expressed at increased levels on activated T cells (Fig. 7b). Contamination with Leu-12-positive B cells was $3 \pm 1 \%(n=3)$ and with macrophages $5.6 \pm 1.3 \%(n$

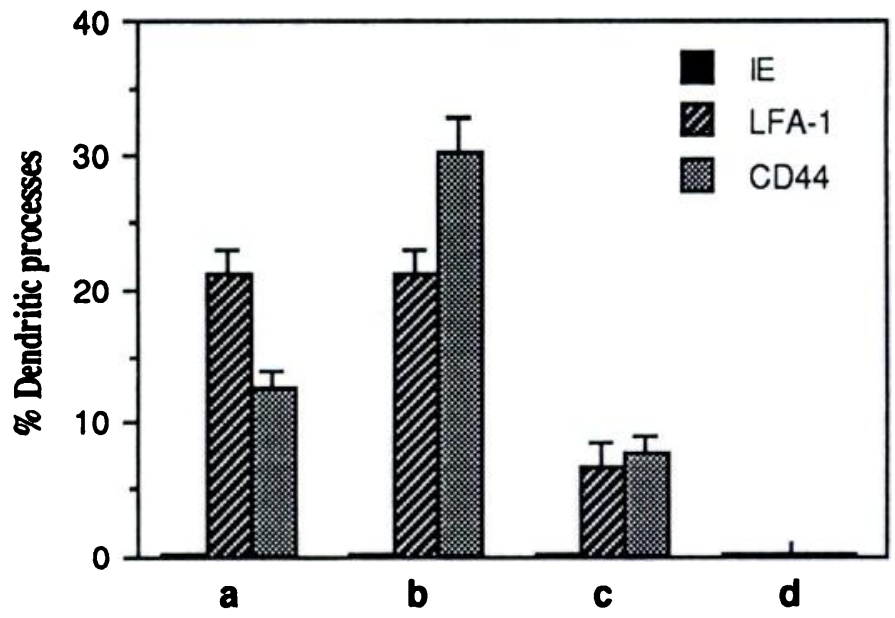

Fig. 5. Addition of tyrosine kinase inhibitor herbimycin $\mathrm{A}$ with antibodies. Peripheral blood lymphocytes were preactivated for $72 \mathrm{~h}$ in the presence of $5 \mathrm{ng} / \mathrm{ml} \mathrm{PMA} \mathrm{(a)} \mathrm{and} 5 \mathrm{ng} / \mathrm{ml} \mathrm{PMA}$ and OKT3 (b). Subsequently, $5 \mathrm{ng} / \mathrm{ml}$ PMA and OKT3-preactivated cells were incubated for $4 \mathrm{~h}$ with immobilized antibodies to LFA-1 (hatched square), CD44 (dotted square), and an irrelevant antibody (black square), in the presence of herbimycin $A$ at concentrations of 2 and $4 \mu \mathrm{M}$ (c and d). Results are shown as mean and SE of triplicate counts in a representative experiment $(n=3)$. 


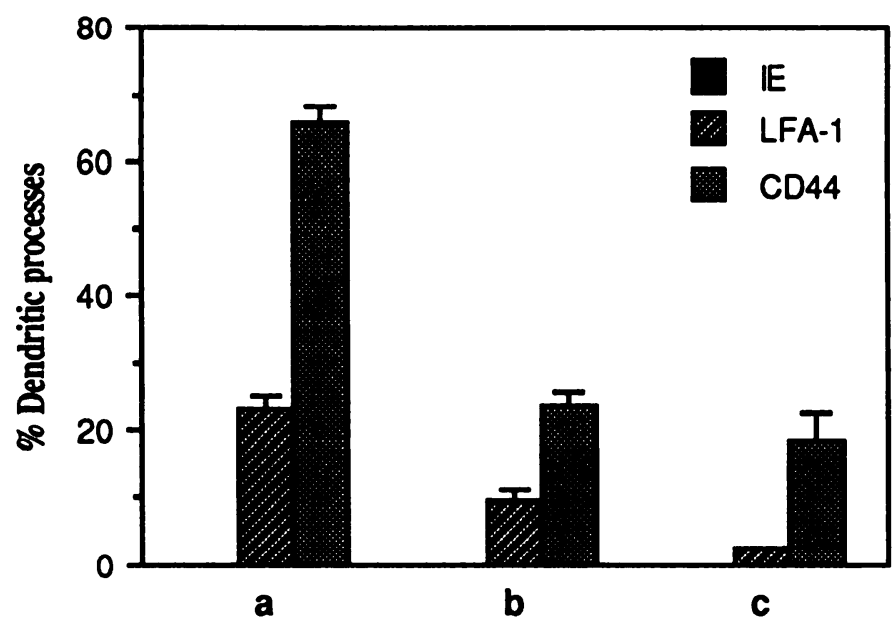

Fig. 6. Addition of the protein synthesis inhibitor cycloheximide and the messenger RNA inhibitor actinomycin D with antibodies. Peripheral blood lymphocytes were preactivated for $72 \mathrm{~h}$ with $25 \mathrm{ng} / \mathrm{ml} \mathrm{PMA} \mathrm{(a).} \mathrm{In} \mathrm{addition,}$ preactivated cells were incubated with immobilized antibodies to LFA-1 (hatched square), CD44 (dotted square), and an irrelevant antibody to mouse MHC, anti-IE (black square) in the presence of $1 \mu \mathrm{g} / \mathrm{ml}$ cycloheximide (b) and $1 \mu \mathrm{g} / \mathrm{ml}$ actinomycin $D(c)$. Results are shown as mean and SE of triplicate counts in a representative experiment $(n=4)$.

$=3$ ) at $72 \mathrm{~h}$. Of particular note is the change in the pattern of expression of LFA-1 (SPV-L-7) (Fig. 7c). This pattern changes from a biphasic pattern observed on resting $T$ cells to a uniphasic intermediate pattern. Similar changes were observed using two other clones MHM-24 and Immunotech 25.3 (data not shown).

\section{Phenotype of cells expressing dendritic processes}

Because there was a small proportion of contaminating B cells and macrophages, we wished to exclude the possibility that they might be among the cells that produced dendritic processes. In view of the data indicating that activation with PMA down-regulated CD3 while up-regulating CD2, we elected to study the dendritic cells for expression of CD2. To do this we utilized a staining step with Leu-5b, an IgG2a antibody to CD2, and an isotype-specific second antibody. As can be seen, the majority of cells that developed dendritic processes in response to anti-LFA-l stimulation strongly expressed CD2 (Fig. 8). In addition, CD2 expression appeared to be distributed along the dendritic processes.

\section{Cytoskeletal inhibitors}

The cytoskeletal inhibitors cytochalasin B and colchicine inhibited the development of these processes completely, whereas they were only partially inhibited by incubation with hydroxyurea, which blocks cellular proliferation (Table 3). Vinblastine, which blocks microtubule assembly, also inhibited the production of dendrites.

\section{DISCUSSION}

Integrin molecules have previously been demonstrated to have signaling properties. Antibodies to LFA-1 have been shown to potentiate calcium flux in $T$ cells stimulated through CD3 [6]. In other studies, immobilized anti-LFA-1 was comitogenic for proliferation of cloned cytolytic $T$ cells [13] and for human peripheral blood $T$ lymphocytes in the presence of PMA [14]. In addition, certain monoclonal antibodies to LFA-l are capable of inducing homotypic aggregation [12].

In these studies a monoclonal antibody to LFA-l $\alpha$ was capable of transducing a signal for the development of dendritic processes in activated human $T$ cells. This signaling event required prior activation with phorbol esters or through the CD3 receptor-associated complex. These findings are not directly comparable to results of studies of homotypic aggregation in short-term stimulated $\mathrm{T}$ cells $[15$, 16]. Homotypic aggregation can be induced by PMA, antiCD3, anti-LFA-1 $\alpha$, or anti-CD44 within $4 \mathrm{~h}$ and this is inhibited by anti-LFA-l. Although the signaling event in response to anti-LFA-l in the current studies is in itself rapid, with maximum effects seen at $4 \mathrm{~h}$, a 3-day activation sequence with PMA is required for maximum signaling. Furthermore, the effect appears to be epitope specific, as other monoclonal antibodies to LFA-1 either fail to induce dendrite formation or induce homotypic aggregation. Previous studies have demonstrated changes in epitopes on
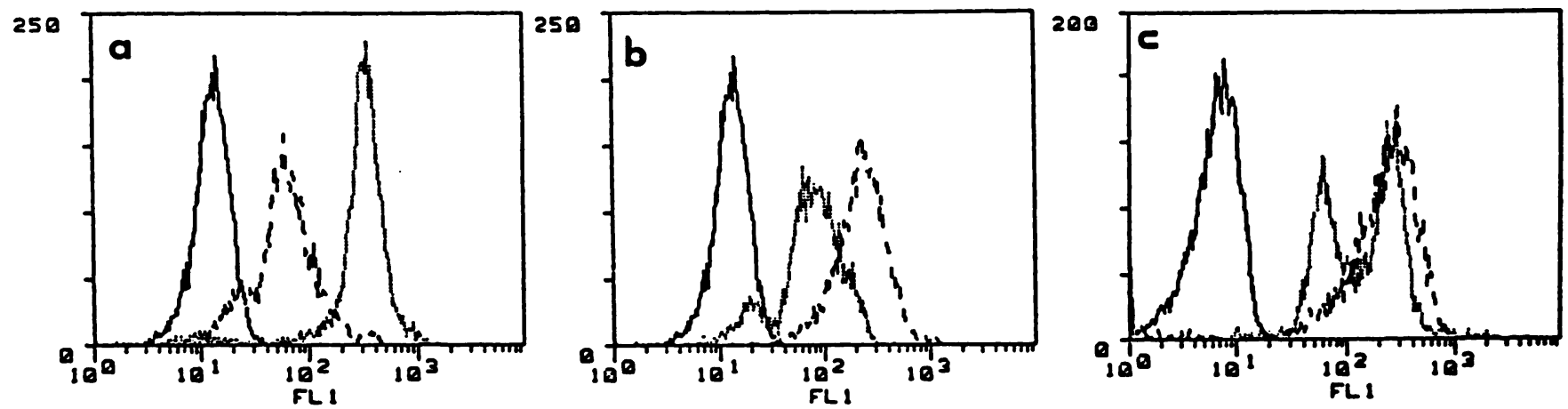

Fig. 7. Expression of CD3 (a), CD2 (b), and LFA-1 (c) on resting (;xx) and 3-day PMA-activated (;xx) peripheral blood T cells on FACScan analysis. Background control with fluoresceinated second antibody is also illustrated (solid line). (a) PMA induces down-regulation of CD3 surface expression, which is maintained for $72 \mathrm{~h}$. By contrast, expression of CD2 is increased (b). (c) Resting peripheral blood lymphocytes have both LFA-1 ${ }^{\text {hi }}$ and LFA- $1^{\text {lo }}$ populations, whereas cells activated with PMA have a single peak of expression. 

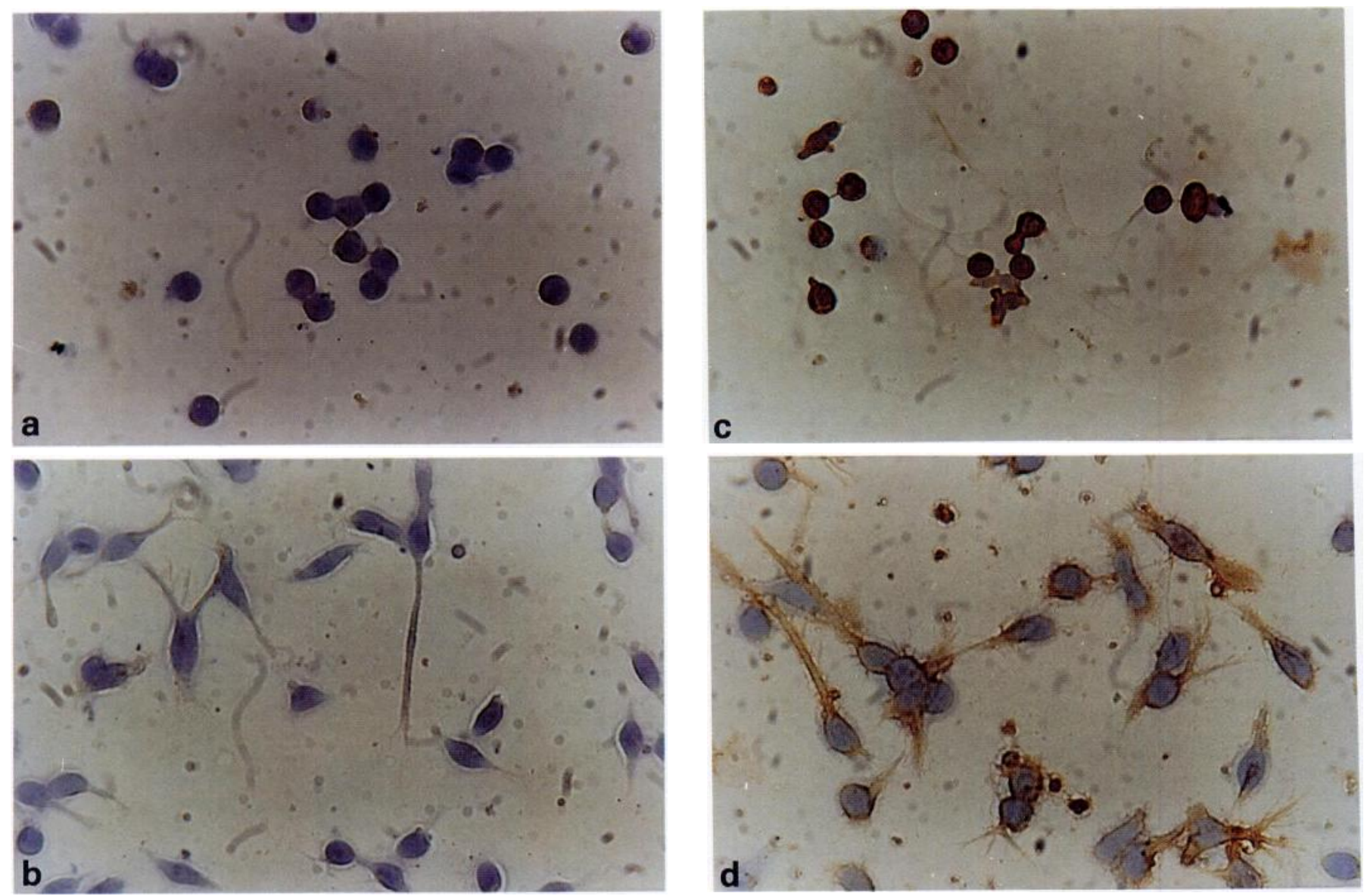

Fig. 8. CD2 expression on peripheral blood lymphocytes stimulated with anti-LFA-1 monoclonal antibody SPV-L7. Resting and PMA-stimulated T cell populations following 3-day culture were stimulated with immobilized anti-LFA-1 monoclonal antibody (IgGl) for $4 \mathrm{~h}$ and then stained for CD2 expression using monoclonal antibody Leu-5b, which is an IgG2 isotype. Thus, the $\mathrm{T}$ cell origin of cells expressing dendritic processes can clearly be determined. (a) and (b) show resting and 3-day-activated cells stained with the isotype-specific second antibody alone; (c) (unstimulated) and (d) (stimulated) demonstrate $T$ cells stained using the anti-CD2 antibody. Clearly, $T$ cells expressing CD2 may be stimulated to develop dendritic processes on stimulation with anti-LFA-1. CD2 expression appears to be distributed along the processes in many of these cells.

LFA-1 and in LFA-1 avidity following short-term activation of $T$ cells with anti-CD3 or PMA $[7,17,18]$. The activation epitope recognized by the NK1-L16 molecule is expressed on $100 \%$ of $\mathrm{T}$ cells at $24 \mathrm{~h} \mathrm{[7]}$ and the expression does not appear to increase significantly between 24 and $72 \mathrm{~h}$. The time sequence of our study with maximal effects at $72 \mathrm{~h}$ suggests that factors other than induction of the NKl-L16 epitope are responsible for these results. Thus, this cy- toskeletal reorganization requires prior priming of the cells by $\mathrm{T}$ cell activation. Furthermore, this effect is not simply due to an increase in LFA-1 expression, because up to $50 \%$ of resting cells are LFA- ${ }^{\text {hi }}$.

Responsiveness to anti-LFA-1 required preactivation with PMA and was blocked by preincubation with protein kinase $C$ inhibitors, staurosporine and Ro-31-8220. The effects of PMA are largely mediated by activation of PKC,

TABLE 3. Effects of Cytoskeletal Poisons on Induction of Dendritic Processes ${ }^{a}$

\begin{tabular}{lccccc}
\hline \hline & & \multicolumn{2}{c}{ T cells expressing dendritic processes $(\%)$} \\
\cline { 2 - 6 } & No antibody & Anti-LFA-I & Anti-DR & Anti-TrR & Anti-ABC \\
\hline Medium alone & $<1$ & 52 & $<1$ & $<$ & 29 \\
Colchicine, $50 \mu \mathrm{M}$ & $<1$ & $<1$ & $<1$ & $<1$ & $<1$ \\
Hydroxyurea, $1 \mathrm{mM}$ & 2 & 28 & $<1$ & $<$ & $<1$ \\
Vinblastin, $100 \mathrm{nM}$ & $<1$ & $<1$ & $<1$ & $<1$ & $<1$ \\
Cytochalasin, B $10 \mu \mathrm{g} / \mathrm{ml}$ & 0 & $<1$ & $<1$ & $<1$ \\
\hline
\end{tabular}

'T lymphocytes obtained from peripheral blood by Ficoll-Hypaque sedimentation followed by sequential nylon wool and plastic adherence steps were incubated in the presence or absence of $25 \mathrm{ng} / \mathrm{ml}$ PMA for 24,48 , and $72 \mathrm{~h}$ before stimulation with immobilized antibodies to LFA-1, HLA-DR, transferrin receptor, and class I molecules in Labtek chamber slides. Cytoskeletal poisons were added to wells. Following $\mathbf{4} \mathrm{h}$ of stimulation, the percentage of cells expressing dendritic processes was counted using a Nikon phase-contrast microscope. Results are expressed as mean of four experiments (SEM < 10\% in all cases). Stimulation with antitransferrin receptor receptor antibody resulted in spreading of cells rather than extension of long dendritic processes. 
an enzyme involved in signal protein phosphorylation [19] and transcription regulation [20]. Thus the synergistic effects of PMA in our system may reflect either direct effects on transcription of cytoskeletal genes or regulatory effects mediated by phosphorylation of cytoskeletal elements or signal molecules such as LFA-1. For example, it has been demonstrated that vimentin is a substrate for PKC and is phosphorylated by the effects of phorbol esters [21]. Similarly, PKC activation results in expression of the intermediate filament neurofilament and increased levels of phosphorylated neurofilament in T lymphocytes [22]. Furthermore, activation of $T$ cells through the $T$ cell receptor results in the physical association of LFA-1 with the actinbased cytoskeleton, possibly mediated through PKC [23].

The $72 \mathrm{~h}$ required for maximal effect of PMA is a period considerably longer than that required for simple PKC-induced phosphorylation and suggests that a downstream effect of PKC activation, possibly new protein synthesis, is required. It is notable that LFA-1-mediated binding to human umbilical vein endothelial cells required $24-48 \mathrm{~h}$ of incubation for maximal effect [24]. The mechanism by which LFA-l transduces its signal is unclear. Although anti-LFA-1 has been shown to potentiate calcium flux in certain circumstances, it fails to induce calcium flux when used in isolation [6]. Preliminary experiments using the calcium ionophore ionomycin have failed to reproduce the effects of anti-LFA-1 (data not shown).

The finding that the stimulation of these morphological changes appears to be epitope specific is not in itself surprising. Other integrins such as the VLA-4 molecule may bind to a number of ligands, including vascular cell adhesion molecule (VCAM), fibronectin, and other as yet uncharacterized molecules [25]. LFA-1 has multiple ligands including ICAM-1 [25], ICAM-2 [26], and ICAM-3 [27]. The observation that ICAM-1 inhibited both morphological changes and homotypic aggregation could suggest multiple binding sites on the ICAM-1 molecule. Alternatively, binding of the molecule to soluble ICAM-1 could sterically alter the molecule so that it is unable to respond to stimuli through discrete epitopes.

The finding that soluble ICAM-1 also inhibited signaling through CD44 could suggest that sICAM-1/LFA-1 interactions could result in a negative signal that blocks cytoskeletal rearrangement. An alternative explanation for differences between antibodies in terms of signals transduced could be that different affinities could induce differential effects related to the degree of receptor occupancy or clustering. In the case of the $\alpha_{5}$ integrin, such differences may be observed in relation to signaling induced by RGD sequences on fibronectin and signaling through antibody [28].

The induction of dendritic processes in these cells clearly involves significant reorganization of the cytoskeleton. This reorganization is inhibited by cytoskeletal inhibitors. The net effect of this cytoskeletal rearrangement is to increase dramatically the number of potential intercellular signaling events that may occur between the stimulated cell and the cells at its site of action. Of note, the CD2 molecule appeared to be redistributed along the dendritic processes. This may represent increased access to accessory cells presenting antigen. However, it has been demonstrated that cells that express the $\gamma \delta \mathrm{T}$ cell receptor tend to adopt a dendritic phenotype, with potential implications with regard to locomotion [29]. Changes similar to those reported here have been observed in large granular lymphocytes migrating on ICAM-1 lipid bilayers [30]. The cytoskeletal changes observed could thus represent the induction of a locomotion-associated phenotype. Such changes could be important in migration of lymphocytes through gaps in tight junctions of endothelial cells. This effect is not specific to LFA-1 and is also stimulated by anti-CD44, which is also a cytoskeleton-linked protein [31]. Notably, studies of the migration of lymphocytes through endothelial cell tight junctions have revealed that this can be blocked by monoclonal antibodies to CD44 and LFA-1 $\alpha$ (but not CD18) [24]. Similar induction of morphological change has been observed in relation to a monoclonal antibody to a $20-\mathrm{kD}$ protein on Jurkat cells [32]. As both CD44 and LFA-1 are involved in the adhesion of activated lymphocytes to high endothelial venules, this could suggest that the observed morphological changes represent an important step in T cell migration through tight junctions. The signaling events required for this process involve both protein kinase $\mathrm{C}$ and tyrosine kinases. However, the interactions between these signaling events remain complex [33].

In conclusion, monoclonal antibodies to LFA-1 $\alpha$ and CD44 stimulate the induction of a dendritic phenotype in activated human $T$ lymphocytes. Induction of such a phenotype may be a necessary step for the migration of lymphocytes through gaps in endothelial tight junctions. The generation of such a phenotype also significantly increases the surface area of the cell that is accessible for cell-to-cell contact and signaling.

\section{ACKNOWLEDGMENTS}

Dermot Kelleher is a Wellcome Senior Fellow in Clinical Science. This work was partially supported by a grant from the Arthritis Foundation of Ireland.

\section{REFERENCES}

1. Hynes, R.0. (1987) Integrins: a family of cell surface receptors. Cell 48 , 549-554.

2. Sanchez-Madrid, F., Nagy, J.A., Robbins, E., Simon, P., Springer, T.A. (1983) A human leukocyte differentiation family with distinct $\alpha$-subunits and a common $\beta$-subunit: the lymphocyte function-associaled antigen (LFA-1), the C3bi complement receptor (OKM1/Mac-1), and the p150,95 molecule. J. Exp. Med. 158, 1785-1803.

3. Staunton, D.E., Dustin, M.L., Erickson, H.P., Springer, T.A. (1990) Functional cloning of ICAM-2, a cell adhesion ligand for LFA-1 homologous to ICAM-1. Nature 339, 61-64.

4. Davignon, D., Martz, E., Reynolds, T., Kurzinger, K., Springer, T.A. (1981) Lymphocyte function-associated antigen l (LFA-1): a surface antigen distinct from Lyt-2/3 that participates in T-lymphocyte-mediated killing. Proc. Natl: Acad. Sci. USA 78, 4535-4541.

5. Rothlein, R., Springer, T.A. (1986) The requirement for lymphocyte function-associated antigen $l$ in homotypic leukocyte adhesion stimulated by phorbol ester. J. Exp. Med. 163, 1132-1142.

6. Wacholtz, M.S., Patel, S.S., Lipsky, P.E. (1989) Leukocyte function-associ- 
ated antigen $l$ is an activation molecule for human T cells. J. Exp. Med. 170 , $431-448$.

7. van Kooyk, Y., Weder, P., Hogervorst, F., Verhoeven, A.J., Van Seventer, G. te Velde, A.A., Borst, J., Keizer, G.D., Figdor, C.G. (1991) Activation of LFA-1 through a $\mathrm{Ca}^{2+}$ dependent epitope stimulates lymphocyte adhesion. J. Cell Biol. $112,345-354$.

8. Kelleher, D., Murphy, A., Cullen, D. (1990) Leukocyte function-associated antigen 1 (LFA-1) is a signalling molecule for cytoskeletal changes in a human T cell line. Eur. J. Immunol. 20, 2351-2354.

9. Burn, P., Kupffer, A., Singer, S.J. (1988) Dynamic membrane-cytoskeletal interactions: association of integrin and talin arises in vivo after ester treatment of peripheral blood lymphocytes. Proc. Natl. Acad. Sci. USA 85 , 497-501.

10. Kupfer, A., Singer, S.J. (1989) The specific interaction of helper T cells and antigen-presenting $B$ cells. IV. Membrane and cytoskeletal reorganizations in the bound T cell as a function of antigen dose. J. Exp. Med. 170, 1697-1713.

11. Geppert, T.D., Lipsky, P.E. (1991) Association of various T cell surface molecules with the cytoskeleton: effect of cross-linking and activation. $J$. Immunol. 146, 3298-3305.

12. Landis, R.C., Bennett, R.I., Hogg, N. (1993) A novel LFA-1 activation epitope maps to the I domain. J. Cell Biol. 120, 1519-1527.

13. Pircher, H., Groscurth, P., Baumhutter, S., Auget, M., Zinkernagel, R.M., Hengartner, H. (1986) A monoclonal antibody against altered LFA-1 induces proliferation and lymphokine release of cloned T cells. Eur. J. Immunol. 16 , 172-181.

14. Carrera, A.C., Rincon, M., Sanchez-Madrid, F., Lopez-Botete, M., de Landazurei, M.O. (1988) Triggering of comitogenic signals in T-cell proliferation by anti LFA-1 (CD18, CD1 la), LFA-3, and CD7 monoclonal antibodies. J. Immunol. 141, 1919-1924.

15. Dustin, M.L., Springer, T.A. (1989) T-cell receptor cross-linking transiently stimulates adhesiveness through LFA-1. Nature 341, 619-624.

16. Koopman, G., van Kooyk, Y., de Graaff, M., Meyer, C.J.L., Figdor, C.G., Pals, S.T. (1990) Triggering of the CD44 antigen on T lymphocytes promotes adhesion through the LFA-1 pathway. J. Immunol. 145, 3589-3593.

17. Lollo, B., Chan, K.W.H., Hanson, E.M., Moy, V.T., Brian, A.A. (1993) Direc evidence for two affinity states for lymphocyte function-associated antigen 1 on activated T cells. J. Biol. Chem. 268, 21693-21700.

18. Dransfield, I., Hogg, N. (1989) Regulated expression of $\mathrm{Mg}_{8}^{2+}$ binding epitope in leukocyte integrin $\alpha$-subunits. EMBO J. 8, 3759-3765.

19. Nishizuka, Y. (1986) Studies and perspectives of protein kinase C. Science 233, 305-310.

20. Angel, P., Imagawa, M., Chiu, R., Stein, B., Imbra, R.J., Rahmsdorf, H.J., Jonat, C., Herrlich, P., Karin, M. (1987) Phorbol ester inducible genes contain a common cis element recognized by a TPA modulated trans-acting factor. Cell 49, 729-739.

21. Inagaki, M., Nishi, Y., Nishizawa, K., Matsugama, M., Sato, C. (1987) Site-specific phosphorylation induces disassembly of vimentin filaments in vitro. Nature 328, 649-652.

22. Murphy, A., Breen, K.C., Long, A., Feighery, C., Casey, E.B., Kelleher, D. (1993) Neurofilament expression in human T lymphocytes. Immunology 79, 167-170.

23. Pardi, R., Inverardi, L., Rugarki, C., Bender, J.R. (1992) Antigen-receptor complex stimulation triggers protein kinase $\mathrm{C}$-dependent CDIla/CD18-cytoskeleton interaction in T-lymphocytes. J. Cell Biol. 116, 1211-1220.

24. Oppenheimer-Marks, N., Davis, L.S., Lipsky, P.E. (1990) Human T lymphocyte adhesion to endothelial cells and transendothelial migration. J. Immunol. 145, 140-148.

25. Springer, T.A. (1990) Adhesion molecules of the immune system. Nature 346, 425-434.

26. Li, R., Nortamo, P., Kantor, C., Kovanen, P., Timonen, T., Gahmberg, C.G. (1993) A leukocyte integrin binding peptide from intercellular adhesion molecule-2 stimulates T cell adhesion and natural killer cell activity. J. Biol. Chem. 268, $21474-21477$.

27. deFougerolles, A.R., Klickstein, L.B., Springer, T.A. (1993) Cloning and expression of intercellular adhesion molecule 3 reveals strong homology to other immunoglobulin family counter-receptors for lymphocyte function-associated antigen 1. J. Exp. Med. 177, 1187-1192.

28. Miyamoto, S., Akiyama, S.K., Yamada, K.M. (1995) Synergistic roles for receptor occupancy and aggregation in integrin transmembrane function. Science 267, 883-885.

29. Arancia, G., Malomi, W., Iosi, F., Zarcone, D., Cerruti, G., Favre, A., Zeromski, J., Grossi, C.E., Moretta, A. (1991) Morphological features of cloned lymphocytes expressing $\gamma \delta \mathrm{T}$ cell receptors. Eur. J. Immunol. 21, 173-178.

30. Carpen, O., Dustin, M.L., Springer, T.A., Swafford, J.A., Beckett, L.A., Caulfield, J.P. (1991) Motility and ultrastructure of large granular lymphocytes on lipid bilayers reconstituted with adhesion receptors LFA-1, ICAM-1 and two isoforms of LFA-3. J. Cell Biol. 115, 861-871.

31. Kalomiris, E.L., Bourgignon, L.Y.W. (1988) Mouse T lymphoma cells contain a transmembrane glycoprotein (GP85) that binds ankyrin. J. Cell Biol. 105 , 1395-1404.

32. Lin, S.-L., Derr, D., Hildreth, J.E.K. (1992) A monoclonal antibody against a novel 20-kDa protein induces cell adhesion and cytoskeleton-dependent morphological change. J. Immunol. 149, 2549-2559.

33. Clark, E.A., Brugge, J.S. (1995) Integrins and signal transduction pathways: the road taken. Science 268, 233-239. 